\title{
How Do Hospitality and Tourism Undergraduate Students Learn? From a Perspective of Learning Styles
}

\author{
I-Cheng Hsu \\ Taiwan Hospitality and Tourism College, Hualien County, Taiwan \\ Pei-Yi Wu \\ Griffith University, Queensland, Australia
}

\begin{abstract}
This theoretical paper presents the influence of learning styles and culture values on facilitating undergraduate students' learning. Learning styles describe the way people process information. Many learning style inventories have been developed and applied widely, for example, Kolb’s Learning Style Inventory (LSI) and Honey and Mumford's Learning Styles Questionnaire (LSQ). However, limited research has been conducted in the field of hospitality and tourism higher education, particularly in eastern culture. Past research in the hospitality and tourism higher education did not reveal if certain learning styles can contribute to better learning outcomes, however, there is a significant difference in preferred learning styles of students in terms of different cultural values. Therefore, it makes it pivotal to consider the influence of culture difference when examining how learning styles contribute to better learning outcomes in future research. Therefore, hospitality and tourism educators can properly plan useful strategies to accommodate different learning styles and enhance students’ learning.
\end{abstract}

Keywords: learning style, hospitality higher education, culture difference

\section{Introduction}

Learning styles are considered as one factor of success in education and human resource development. Understanding learning styles of students can help educators improve, organize, and validate successful learning for students (Collinson, 2000; Harrelson, Leaver-Dunn, \& Wright, 1998; Pitts, 2009; Romanelli, Bird, \& Ryan, 2009; Wolfe, Bates, Manikowske, \& Amundsen, 2005). Erdem (2003) found that while students perceive that the teaching styles match their preferred learning styles, they demonstrate higher overall educational satisfaction. In addition, Wolfe et al. (2005) argued that by grouping students with different learning styles, students obtain a stronger appreciation for one style of diversity. For human resource development, understanding personal style profiling can improve employee achievement in training programs and increase training efficiency (Buch \& Bartley, 2002; Sadler-Smith, 1996). In addition, comprehending individual learning style will enable practitioners to utilize their own strengths and improve their weaknesses for attaining effective work performance (Berger, 1983; Sadler-Smith, 1996).

I-Cheng Hsu, lecturer, Department of Travel Management, Taiwan Hospitality and Tourism College. Email: cheng@mail.tht.edu.tw.

Pei-Yi Wu, Ph.D. candidate, Department of Tourism, Sport, and Hotel Management, Griffith University. 


\section{Learning Styles}

Learning style refers to an individual's distinctive, habitual, and preferred ways of acquiring, processing, retaining, and applying knowledge, skills, or attitudes through study or experience (Romanelli et al., 2009; Sadler-Smith, 1996). According to Romanelli et al. (2009, p. 1), learning styles are "relatively stable indicators of how learners perceive, interact with, and respond to the learning environment”. Individuals will possess a preference for certain styles (Pheiffer, Holly, \& Andrew, 2005). In order to adapt in different situations at different time, researchers suggest that individuals need to develop a wide range of learning methods rather than rely on a preferred style (Fatt, 2000; Loo, 2002; Sadler-Smith, 1996).

\section{Learning Style Models}

Diverse inventories and models of learning styles have been developed to identify how an individual learns. Coffield, Moseley, Hall, and Ecclestone (2004) reviewed a body of theoretical and empirical research and identified 71 learning style models. However, "Many consist of rather minor adaptations of one of the leading models and therefore lack influence on the field as a whole” (Coffield et al., 2004, p. 1). Coffield et al. (2004) further constructed a continuum of learning styles within which any particular model and inventory of learning styles could be categorized as one of the five families (see Figure 1). The continuum is based on the extent to which the model and instrument developers perceive that learning styles are fixed. In order of the greatest to the least extent, these five families of learning styles along the continuum were: constitutionally based preferences; cognitive structure; stable personality type; flexible stable learning preferences; and learning approaches, strategies, orientations, and conceptions of learning (Coffield et al., 2004).

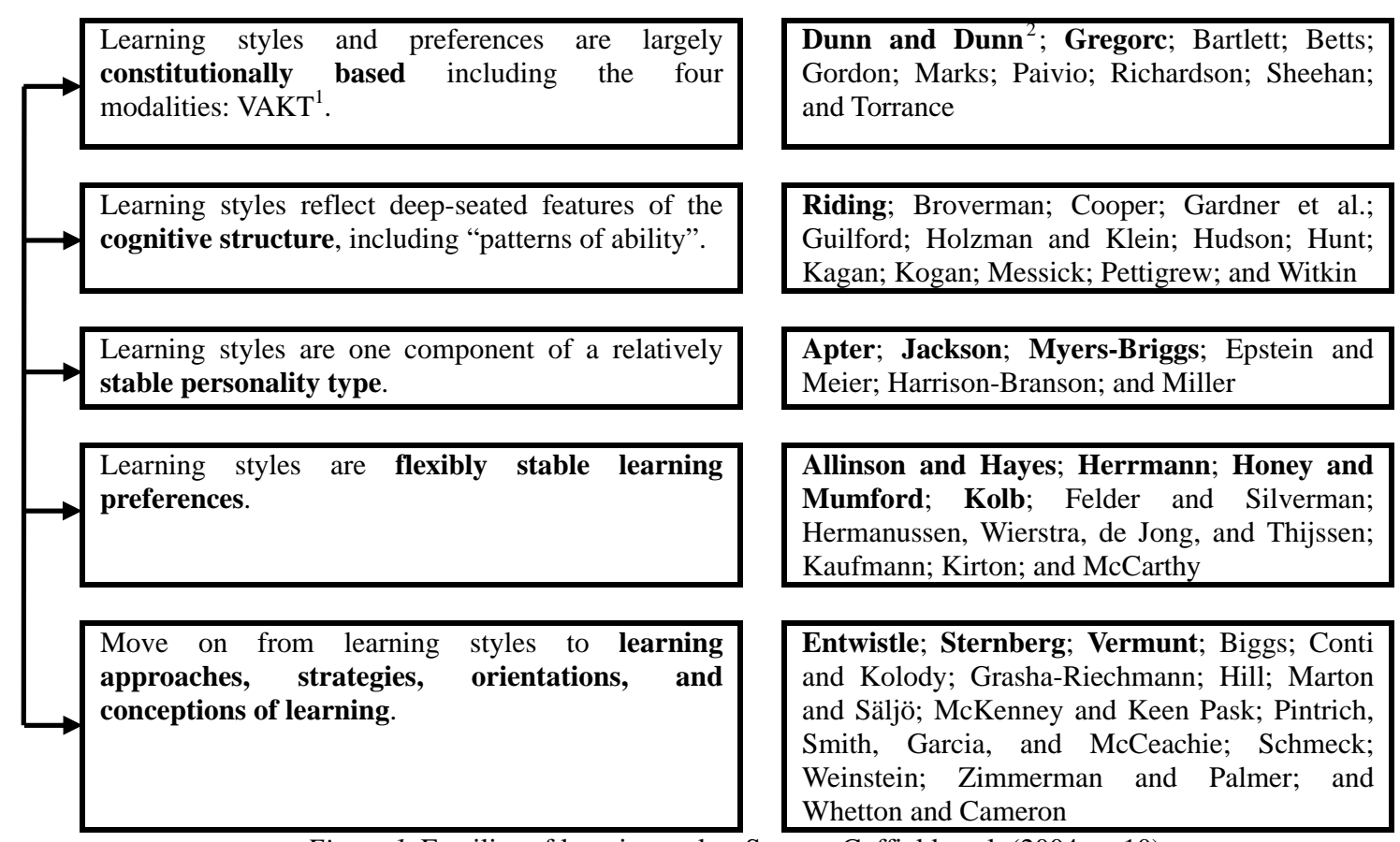

Figure 1. Families of learning styles. Source: Coffield et al. (2004, p. 10).

\footnotetext{
${ }^{1}$ VAKT = Visual, auditory, kinaesthetic, tactile.

2 The models and instruments of learning styles developed by the theorists in bold type are the most influential and potentially influential.
} 
Particular models have become extremely influential and popular. For example, while the Dunn, Dunn, and Price Learning Style Inventory (LSI) is used in a large number of elementary schools in the United States, both Kolb's LSI and Honey and Mumford's Learning Styles Questionnaire (LSQ) are widely known and used in the United Kingdom (Coffield et al., 2004). In the field of hospitality related to learning styles, Kolb's LSI and Honey and Mumford's LSQ have been extensively employed (see Table 1).

Table 1

Summary of Learning Style Studies in Hospitality

\begin{tabular}{|l|l|l|}
\hline Inventory & Kolb’s LSI & Honey and Mumford's LSQ \\
\hline Studies in hospitality & & $\begin{array}{l}\text { Lashley (1999) } \\
\text { Barron and Arcodia (2002) } \\
\text { Lashley and Barron (2006) } \\
\text { Huang and Busby (2007) } \\
\text { Charlesworth (2007; 2008) } \\
\text { Chan and Mak (2010) }\end{array}$ \\
\hline
\end{tabular}

\section{The Kolb’s LSI}

The Kolb's LSI is based on a bipolar view of two learning continuums: perceiving and processing (Buch \& Bartley, 2002; Castro \& Peck, 2005; Coffield et al., 2004; see Figure 2). The vertical axis gauges how learners perceive information through either concrete experience or abstract conceptualization, whereas the horizontal axis measures how learners process and transform information, through either active experimentation or reflective observation (see Figure 2). Through this polarity, Kolb established four types of learning styles (Coffield et al., 2004):

Type 1: The converging style (abstract, active) relies primarily on abstract conceptualization and active experimentation; is good at problem-solving, decision-making, and the practical application of ideas; and is controlled in the expression of emotion and prefers dealing with technical problems rather than interpersonal issues;

Type 2: The diverging style (concrete, reflective) emphasizes concrete experience and reflective observation; is imaginative and aware of meanings and values; adapts by observation rather than by action; and is interested in people and tends to be feeling-oriented;

Type 3: The assimilating style (abstract, reflective) prefers abstract conceptualization and reflective observation; likes to reason inductively and create theoretical models; and is more concerned with ideas and abstract concepts than with people;

Type 4: The accommodating style (concrete, active) emphasizes concrete experience and active experimentation; likes carrying out plans and getting involved in new experiences; is good at adapting to changing circumstances; and solves problems in an intuitive, trial-and-error manner.

\section{The Honey and Mumford's LSQ}

Owing to the low face validity resulting from applying Kolb’s inventory, Honey and Mumford (1986) developed their own model of the learning process (see Figure 3) and instrument by modifying Kolb’s theory. In their model, the learning process is a circular process where learning is considered as a series of experiences: having an experience, reviewing the experience, concluding from the experiences, and planning the next steps (Coffield et al., 2004). The instrument, the LSQ developed by Honey and Mumford (1986), is designed to determine a preferred way of an individual in each of the four learning styles: activists, reflectors, theorists, and 
pragmatists. While an activist is a dynamic learner, a reflector is an imaginative learner. A pragmatist is a commonsense learner, whereas a theorist is an analytical learner (Fatt, 2000). According to Honey and Mumford (1986), a learner should become proficient in all the four learning types.

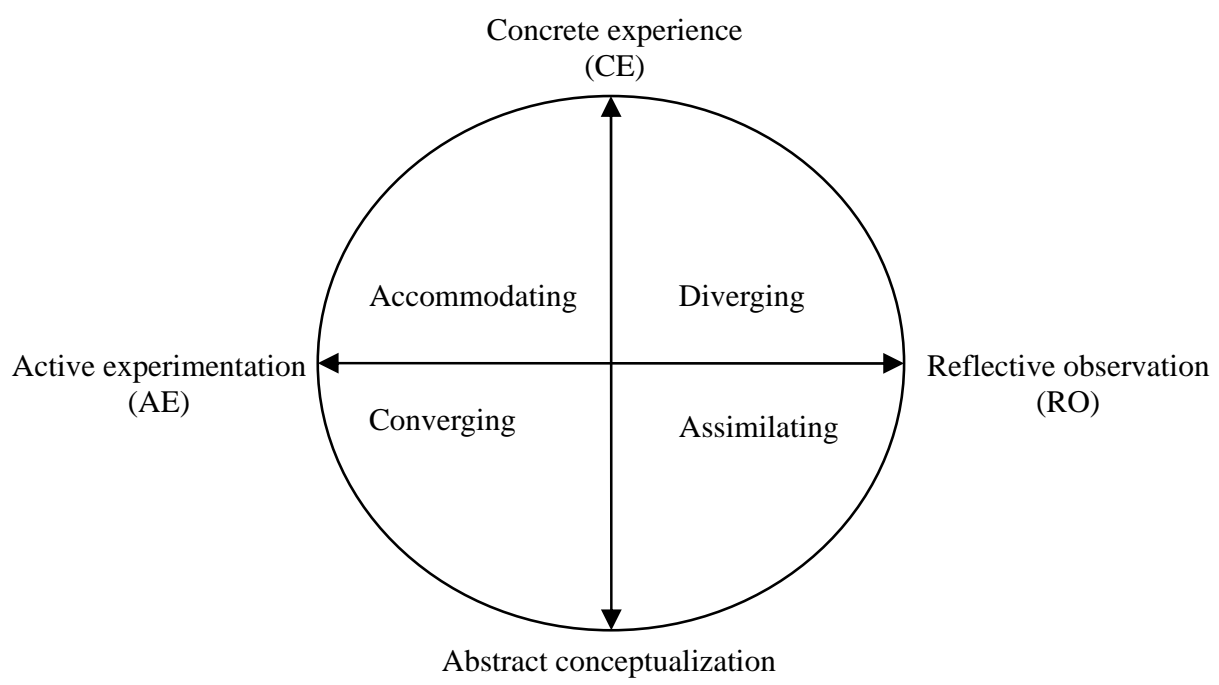

(AC)

Figure 2. Kolb’s four learning styles. Source: Coffield et al. (2004, p. 62).

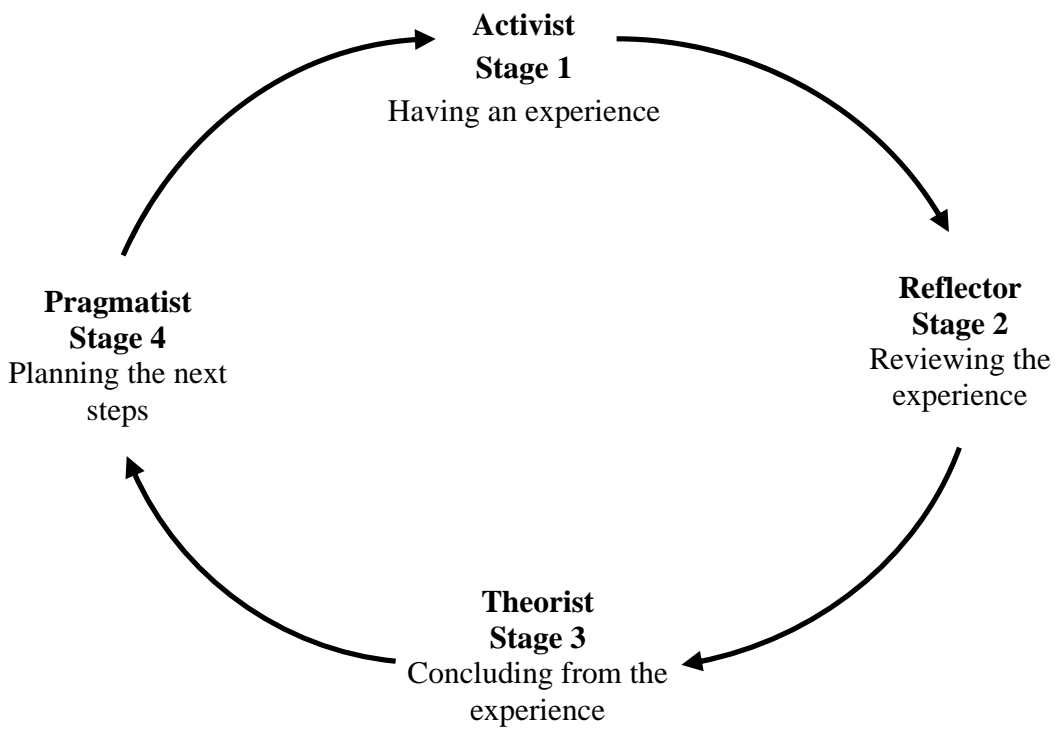

Figure 3. Dimensions of Honey and Mumford’s learning cycle. Source: Coffield et al. (2004, p. 72).

\section{Application of Learning Style Approaches in the Field of Hospitality}

Using Kolb’s LSI, Berger (1983) contended that occupations, gender, and academic performance are characteristics that differentiate among individuals' learning styles. Through chi-square test, the learning styles are significantly different among the students, educators, and managers (Berger, 1983). While hospitality students preferred the diverger learning styles, most hospitality educators were convergers and managers were convergers and accommodators (see Table 2). 
Table 2

Learning Styles of Hospitality Students, Professors, and Managers

\begin{tabular}{llllll}
\hline & & Accommodator & Diverger & Converger & Assimilator \\
\hline \multirow{2}{*}{ Hospitality students } & No. & 69 & 79 & 47 & 46 \\
& $\%$ & 28.6 & 32.8 & 19.5 & 19.1 \\
\hline \multirow{2}{*}{ Hospitality professors } & No. & 4 & 4 & 11 & 7 \\
& $\%$ & 15.5 & 15.5 & 42 & 27 \\
\hline \multirow{2}{*}{ Hospitality managers } & No. & 10 & 8 & 10 & 3 \\
& $\%$ & 32 & 26 & 32 & 10 \\
\hline
\end{tabular}

Note. Source: Berger (1983).

In addition, past research revealed that hospitality students of convergers, assimilators, and accommodators learning styles significantly attained higher academic performance than students of divergers learning styles (Berger, 1983). When comparing students' learning style preferences according to different grade levels, Chan and Mak (2010) reported that good and poor grade students revealed strong preferences in all four learning styles in comparison with students with an average grade. There is no conclusion of which learning style may lead to better academic grades. Similarly, Hung and Busby (2007) contended that the relationship between hospitality students' dominant learning style and their academic achievement is not significant. Erdem (2003) indicated that the more the students are satisfied with instructional methods, the higher performance they achieve. Castro and Peck (2005) supported that no learning style should be better than another. It makes important that educators should find strategies to adapt their teaching styles to accommodate different learning styles of students. Hence, expected learning outcomes can be achieved.

With a closer look at the relationship between cultural backgrounds and learning styles, many researchers advocated the influence of culture on students' learning preferences (Romanelli et al., 2009). In researches using Honey and Mumford's LSQ, western hospitality students show a preference for activist learning, while eastern hospitality students display strong reflector learning preferences (Barron \& Arcodia, 2002; Charlesworth, 2007; 2008; Lashley, 1999; Lashley \& Barron, 2006). However, when studying in western universities, the learning style preferences of eastern students will change during their study (Charlesworth, 2007). Barron and Arcodia (2002, p. 24) investigated "Confucian heritage culture” students studying hospitality and tourism management in Australia and found that these students "adopt an activist style of learning preference similar to their western peers”. Mitsis and Foley (2009) also reported that culture values can better predict students' learning styles than the traditional categories of international and domestic students. They found that students with a student-driven learning style (activist and pragmatist) were positively related to the characteristics of individualism, small power distance, masculinity, low uncertainty avoidance, and short-term orientation (that is, Hofstede's five indexes of national culture dimensions), while students with a teacher-driven learning style (reflector and theorist) were to its opposite. The results enable the conclusion that teacher-driven learning style students are featured with collectivism, large power distance, femininity, high uncertainty avoidance, and high long-term orientation (Confucianism). These imply that students with Confucianism culture values (usually Asian students) tend to present reflector and theorist learning preferences, while students with non-Confucianism culture values (usually western students) are activist and pragmatist in learning. 
Employing the Kolb’s model, Auyeng and Sands (1996) revealed similar findings. They reported that Australian accounting students preferred an accommodator learning style, while students from Hong Kong and Taiwan preferred an assimilator style. Lashley and Barron (2006), using Honey and Mumford's instrument, also supported that students from the United Kingdom (UK), Australia, and other non-Confucian heritage countries (that is, European, American, African, Indonesian, and Thai) revealed a strong activist learning style preference, while students from Confucian cultures scored relatively high in reflector learning style. When adopting the Cognitive Style Index (CSI) in which learning styles are in the continuum of analytic and intuitive, Allinson and Hayes (2000) also supported the grouping in studies of Auyeng and Sands as well as Lashley and Barron. They reported that the intuitive groups were from countries of Anglo, North European, and European Latin regions. Most analytic groups were from eastern countries. Learners with an intuitive preference tend to take actions and think innovatively, while analytic learners prefer to make plans and conceptualize situations. Table 3 summarizes the comparison of culture differences and preferred learning styles.

Table 3

Summary of Learning Style Studies and Cultures

\begin{tabular}{|l|l|l|}
\hline Inventory & Eastern culture & Western culture \\
\hline Kolb’s LSI & & \\
(Auyeng \& Sands, 1996) & Assimilator (abstract and reflective/theorist and & Accommodator (concrete and active/activist \\
Honey and Mumford's LSQ & reflector) & $\begin{array}{l}\text { and pragmatist) } \\
\text { (Lashley \& Barron, 2006) }\end{array}$ \\
$\begin{array}{l}\text { Allison and Hayes’ CSI } \\
\text { Reflector (reflective observation) }\end{array}$ & Analytic (analysis) & \\
\hline
\end{tabular}

Note. Source: Developed for this study.

\section{Conclusion}

Seeing the connection between learning styles and culture values, it is pivotal for hospitality educators and human resource managers to consider how learning styles can be utilized as a meta-cognitive approach to enhance learning. The learning styles describe how people process information in a circular state and the proficiency in all styles is the way to maximize the learning outcomes and therefore attain the purpose of learning. Past research revealed that students (e.g., international students) can be adaptable to the demands of the academic learning environment in which they are situated and thus adopt a different learning style approach that they used to be. Culture values also play a role in influencing students' learning preferences. Although limited evidences have been found to prove how a matched learning and teaching can be practically successful or which learning styles contribute to better learning outcomes in which cultural context, it indeed leaves substantial room for future investigation. A review of the literature shows that there is relatively little learning style research conducted in the field of hospitality and tourism, particularly in the eastern cultures. The future studies should investigate the differences in learning styles of hospitality and tourism undergraduate students in eastern cultures and inform educators of how to adapt their teaching plans, curriculum designs, and instruction and evaluation methods to match students' expectations and accommodate all learning styles in the classrooms.

\section{References}

Allinson, C. W., \& Hayes, J. (2000). Cross-national differences in cognitive style: Implications for management. The International Journal of Human Resource Management, 11(1), 161-170.

Auyeng, P., \& Sands, J. (1996). A cross cultural study of the learning style of accounting students. Accounting and Finance, 36(2), 261-274. 
Barron, P., \& Arcodia, C. (2002). Linking learning style preferences and ethnicity: International students studying hospitality and tourism management in Australia. Journal of Hospitality, Leisure, Sport, and Tourism Education, 1(2), 15-27.

Berger, F. (1983). Disparate learning styles of hospitality students, professors, and managers. International Journal of Hospitality Management, 2(1), 15-23.

Buch, K., \& Bartley, S. (2002). Learning style and training delivery mode preference. Journal of Workplace Learning, 14(1), 5-10.

Castro, O., \& Peck, V. (2005). Learning styles and foreign language learning difficulties. Foreign Language Annals, 38(3), 401-409.

Chan, S., \& Mak, W. M. (2010). The use of learning styles questionnaire in Macao. Industrial and Commercial Training, 42(1), 41-46.

Charlesworth, Z. M. (2007). Educating international hospitality students and managers: The role of culture. International Journal of Contemporary Hospitality Management, 19(2), 133-145.

Charlesworth, Z. M. (2008). Learning styles across cultures: Suggestions for educators. Educating and Training, 50(2), 115-127.

Coffield, F., Moseley, D., Hall, E., \& Ecclestone, K. (2004). Learning styles and pedagogy in post-16 learning: A systematic and critical review. London, UK: Learning and Skills Research Centre. Retrieved from http://sxills.nl/lerenlerennu/bronnen/Learning\%20styles\%20by\%20Coffield\%20e.a..pdf

Collinson, E. (2000). A survey of elementary students' learning style preferences and academic success. Contemporary Education, 71(4), 42-46.

Erdem, M. (2003). Examining the effect of teaching method and learning style on student course achievement for hospitality students (Unpublished doctoral dissertation, University of Nevada, Las Vegas).

Fatt, J. P. T. (2000). Understanding the learning styles of students: Implications for educators. International Journal of Sociology and Social Policy, 20(11/12), 31-45.

Harrelson, G. L., Leaver-Dunn, D., \& Wright, K. E. (1998). An assessment of learning styles among undergraduate athletic training students. Journal of Athletic Training, 33(1), 50-53.

Honey, P., \& Mumford, A. (1986). The manual of learning styles. Maidenhead: Peter Honey Publications.

Huang, R., \& Busby, G. (2007). Activist, pragmatist, reflector, or theorist? In search of postgraduate learning styles in tourism and hospitality education. Journal of Hospitality, Leisure, Sport, and Tourism Education, 6(2), 92-99.

Lashley, C. (1999). On making silk purses: Developing reflective practitioners in hospitality management education. International Journal of Contemporary Hospitality Management, 11(4), 180-185.

Lashley, C., \& Barron, P. (2006). The learning style preferences of hospitality and tourism students: Observations from an international and cross-cultural study. Hospitality Management, 25(4), 552-569.

Loo, R. (2002). A meta-analytic examination of Kolb’s learning style preferences among business majors. Journal of Education for Business, 77(5), 252-256.

Mitsis, A., \& Foley, P. W. (2009). Do business students' culturally anchored values shape student-driven or teacher-driven learning style preferences? Journal of Marketing Education, 31(3), 240-252.

Pheiffer, G. P., Holly, D., \& Andrew, D. (2005). Developing thoughtful students: Using learning styles in an HE context. Education and Training, 47(6), 422-431.

Pitts, J. (2009). Identifying and using a teacher-friendly learning style instrument. The Clearing House, 82(5), 225-231.

Romanelli, F., Bird, E., \& Ryan, M. (2009). Learning styles: A review of theory, application, and best practices. American Journal of Pharmaceutical Education, 73(1), 1-5.

Sadler-Smith, E. (1996). Learning styles: A holistic approach. Journal of European Industrial Training, 20(7), 29-36.

Wolfe, K., Bates, D., Manikowske, L., \& Amundsen, R. (2005). Learning styles: Do they differ by discipline? Journal of Family and Consumer Sciences, 97(4), 18-22. 